\title{
Design, Fabrication, Evaluation and Calibration of an Improvised Soil Permeameter for Measurement of Soil Hydraulic Conductivity
}

\author{
*ALIKA, JO; ADEOGUN, BK; AJIBIKE, MA \\ Department of Water Resources and Environmental Engineering, Ahmadu Bello University, Zaria, Kaduna, Nigeria \\ *Corresponding Author Email: alikajeremiah@gmail.com
}

\begin{abstract}
This study aimed at the design, fabrication, evaluation and calibration of an improvised soil permeameter for measuring saturated soil hydraulic conductivities. A metal support frame with a permissible strength of 50e- $4 \mathrm{~N} / \mathrm{mm} 2$ was made using steel galvanized pipes of $6 \mathrm{~cm} \varnothing$ (internal diameter) and metal flat bars of $8 \mathrm{~cm}$ long and $0.4 \mathrm{~cm}$ thick. The water tank (thickness $0.6 \mathrm{~cm}$, height $28 \mathrm{~cm}$, internal diameter $19 \mathrm{~cm} \varnothing$ ) and permeameter cylinder (thickness $0.6 \mathrm{~cm}$, height $23 \mathrm{~cm}$, internal diameter $19 \mathrm{~cm}$ ) were both made of Perspex glass material. An electromechanical measuring device which was programmed and operated wirelessly was designed and constructed to measure head-in and head-out parameters. To calibrate the improvised soil permeameter, sampled and particle analysed soils from different locations within Zaria metropolis, were a test run on both foreign and improvised soil permeameters and their respective Ksat readings were subjected to regression analysis. According to the $R^{2}$ values, the generated $3^{\text {rd }}$ order polynomial regression equation from the Ksat readings of both foreign and improvised soil permeameter had a satisfactory $R^{2}$ value of 0.985 .
\end{abstract}

\section{DOI: https://dx.doi.org/10.4314/jasem.v24i5.22}

Copyright: Copyright (C) 2020 Alika et al. This is an open access article distributed under the Creative Commons Attribution License (CCL), which permits unrestricted use, distribution, and reproduction in any medium, provided the original work is properly cited.

Dates: Received: 11 March 2020; Revised: 22 April 2020; Accepted: 16 May 2020

Keywords: Permeameter, Hydraulic Conductivity, Electromechanical, Saturated, Automation

Soil, a naturally occurring material present on the surface of the earth is of utmost importance in various civil engineering works such as the construction of multi-story buildings, bridges, highways, canals, etc (Gupta et al., 2016). Proper measurement/evaluation of soil permeability is required for calculating the seepage under hydraulic structures and water quantities during dewatering activities. Soil permeability is affected by several factors including voids ratio, distribution of inter-granular pores, and degree of saturation. The laboratory device used to measure hydraulic conductivity is a 'permeameter'. The two kinds of permeameters commonly used are the 'constant-head' and 'falling-head' permeameter. The difference in the application of these two permeameters is largely dictated by the volume of water flowing through the sample (EijkelKamp Soil \& Water Laboratory permeameters user manual). Automation can be defined as the technology by which a process or procedure is performed without human assistance (Groover and Mikell, 2014). Automation has been achieved by various means including mechanical, hydraulic, pneumatic, electrical, electronic devices and computers, usually in combination as a kind of feasible sensor with advantages of low cost, low power consumption and strong adaptability (Fabian et al., 2014). Programming involves activities such as analysis, developing understanding, generating algorithms, verification of requirements of algorithms including their correctness and resources consumption, and implementation (commonly referred to as coding (Shaun, 2014)) of algorithms in a target programming language. Automation is essential for many scientific and clinical applications (Carvalho, 2016). Therefore, automation has been extensively employed in laboratories. From as early as 1980, fully automated laboratories have already been working ("Robotic Laboratory Automation," 2002). The need for a more precise and accurate way of taking measurements arose haven observed a foreign designed soil permeameter with a probable source of error from its manual graduated adjustment knob which could alter the output readings in terms of the head of water above the soil sample being tested. Hence, this probable source of error was not only correct but also an attempt was made to make an enhanced and modified system available. Also, with the current economic situation in Nigeria, purchasing a standard soil permeameter could cost a fortune. Therefore, there is need to come up with a relatively cheaper substitute design. The objective of this study is to evaluate and calibrate an improvised soil permeameter for determination of saturated hydraulic conductivity of different soil samples. 


\section{MATERIALS AND METHODS}

The design of the soil permeameter was done in a similar principle as the Eijkelkamp Agrisearch Equipment. Two cylindrical-shaped containers made of Perspex glass were used to hold water at different heights.

Materials Used and Their Purposes: The following are the list of materials (Plate 1) used and their functions. Also, the criteria for selecting these materials are briefly explained.

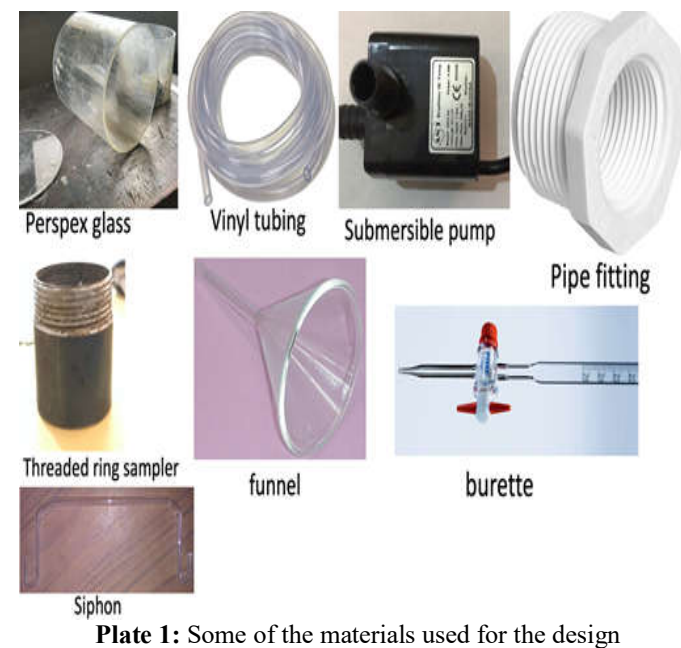

Perspex Glass: This is the material used to make the cylindrical water tank at the base and the permeameter cylinder at the top that holds both water and soil samples to be tested. The criteria for this material selection was due to its tensile strength and physical transparency.

Vinyl Tubing: This served as the connection between the top and bottom cylinder. It conveys water with the aid of a submersible pump embedded in the bottom cylinder (water tank) to the top permeameter cylinder where a constant water level is to be maintained. The criteria for selection of this was due to its smooth internal surface which reduces friction and also due to its flexibility and lightweight. It has an internal diameter of $9.53 \mathrm{~mm} \emptyset$.

ANT Brushless DC Submersible pump: Primarily used to convey water from the bottom cylinder to the top cylinder. The basis of selection was due to its silent smooth running and compact size. The pump ratings are as follows; Max head: $3.0 \mathrm{~m}$, Max flow: $240 \mathrm{~L} / \mathrm{H}$, Power: $4.8 \mathrm{~W}$, Voltage: DC $12 \mathrm{~V}$.

Valve: This was primarily used to control the outflow of water from the permeameter cylinder to the water tank to maintain a desirable constant water level.

Glass Siphon: Though fragile, but durable in the sense that it has less surface friction compared to rubber or plastic and also has a less chemical reaction to solutions. The effect of the siphon is to create a difference in water level inside and outside the ring holder. This difference induces a continuous flow of water through the sample. The internal diameter of the siphon is $5 \mathrm{~mm}$.

Ring samplers: These are precisely cut galvanized pipes of $5 \mathrm{~cm}$ height and $5 \mathrm{~cm}$ internal diameter. With one end chamfered and the other end externally threaded, they were used to collect soil samples from the site and attached to their holders.

Ring Holders: The ring samplers were attached to the ring holders and placed inside the permeameter cylinder. Hence the ring holders hold the ring samplers that contain the soil samples in place. The ring holder is made of a cylindrical PVC pipe of $26.67 \mathrm{~mm} \varnothing$ internal diameters, $140 \mathrm{~mm}$ height and a PVC adaptor of dimension 2 in. x $1 \frac{1}{2}$ in with internal threading.

Permeable Membrane: Typically, this is a sieve of pore size $0.7 \mathrm{~mm}$ which served to avoid direct contact of the soil sample with water to hold the soil particles intact against any disturbance.

Burette: This is a laboratory apparatus used to measure the height of the liquid in its column. In this case, we used it to measure discharge. This was done using a timer.

Funnel: The funnel is generally an apparatus used to conveniently transfer a liquid from one container to another that is when pouring a liquid such as water. In this case, we used the funnel to safely collect and connect the water from the siphon to the burette.

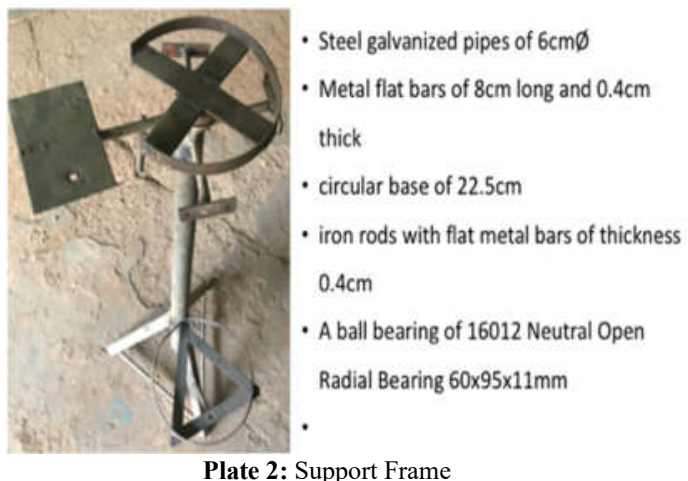

Plate 2: Support Frame 
CAD of Soil Permeameter: Computer-aided design (CAD) involves creating computer models defined by geometrical parameters. CAD systems enable designers to view objects under a wide variety of representations and to test these objects by simulating real-world conditions INC, (2006). SolidWorks is a system of automated design, engineering analysis and preparation of production of products of any complexity and purpose. SolidWorks is the core of the integrated enterprise automation complex. The various parts of the soil permeameter were designed using SolidWorks with real-time dimensions. All parts were afterwards integrated as an assembly to constitute the Soil Permeameter.

Frame Design: The frame was made from steel galvanized pipes of $6 \mathrm{~cm} \varnothing$ (internal diameter) and metal flat bars of $8 \mathrm{~cm}$ long and $0.4 \mathrm{~cm}$ thick which were welded on a long thick cylindrical metal bar in a cross-like manner. The thick cylindrical bar forms the fulcrum or centre of the metal bars. A ball bearing of 16012 Neutral Open Radial Bearing 60 x 95 x $11 \mathrm{~mm}$ was attached to this thick cylindrical bar and inserted into a larger hollow cylindrical pipe of $6.5 \mathrm{~cm}$ internal diameter to create a rotational effect. A circular base of $22.5 \mathrm{~cm}$, where the water tank would sit was welded to the external hollow cylindrical pipe at a height of 26 $\mathrm{cm}$ from the ground surface. Also, at a distance of 70 $\mathrm{cm}$ along with the height of the external cylindrical pipe, iron rods with flat metal bars of thickness $0.4 \mathrm{~cm}$ and countersunk holes of $0.5 \mathrm{~mm} \varnothing$, attached at one end, were welded to the external cylindrical pipe. This will serve to hold the three burettes in place. To make this whole setup stand firmly, a support stand welded in a triangular pattern was provided as shown in Plate 2 .

Permeameter Cylinder Design: Parameters of the top and bottom cylinder are shown in Table 1 below.

Table 1: Features of Selected Perspex Glasses

\begin{tabular}{llllll}
\hline & $\begin{array}{l}\text { Thickness } \\
(\mathrm{cm})\end{array}$ & $\begin{array}{l}\text { Height } \\
(\mathrm{cm})\end{array}$ & $\begin{array}{l}\text { Internal } \\
\text { diameter } \\
(\mathrm{cm})\end{array}$ & $\begin{array}{l}\text { Volume Force } \\
\left(\mathrm{cm}^{3}\right)\end{array}$ & $\begin{array}{l}\text { Ford) } \\
(\mathbf{k N D})\end{array}$ \\
\hline $\begin{array}{l}\text { Top } \\
\text { cylinder }\end{array}$ & 0.6 & 23 & 19 & 6523.79 & 0.064 \\
$\begin{array}{l}\text { Bottom } \\
\text { sylinder }\end{array}$ & 0.6 & 28 & 19 & 7941.99 & 0.078 \\
\hline
\end{tabular}

The cylinder material was made of Perspex. The entire height of the permeameter cylinder. (Plate 3 ) is $23 \mathrm{~cm}$. There is barrier support also created at about $16 \mathrm{~cm}$ from the bottom of the permeameter cylinder height, inside the cylinder. This barrier serves as a support to the ring samplers and ring holders. This barrier support has three holes of about $5.5 \mathrm{~cm} \varnothing$ equidistant to one another. A valve is also fixed at about $19 \mathrm{~cm}$ along the height of the permeameter cylinder. The valve serves as a regulatory device for keeping the water in the cylinder at a constant level. Also, just above the base of the permeameter cylinder, an inlet Vinyl tubbing from the pump in the water tank is inserted and glued.

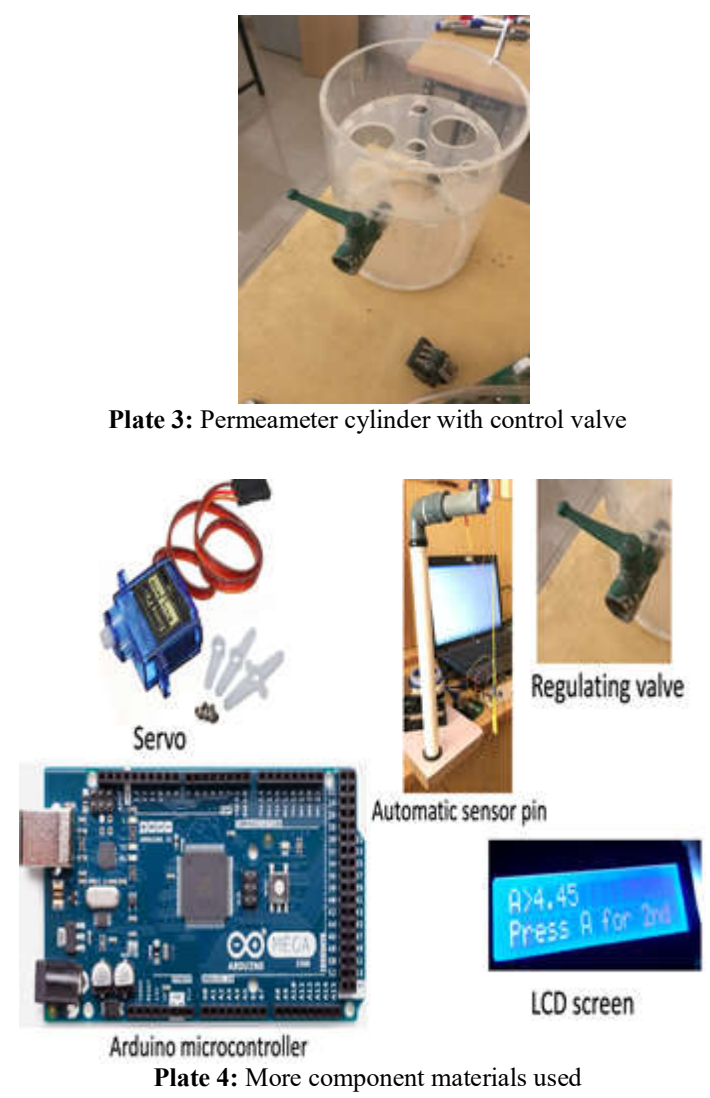

Design of Electromechanical Measuring Device: The electromechanical measuring device was also identified as a millage gauge as shown in Plate 4. The construction of this device was done in two stages the physical material component (the hardware) stage and the programming component (software) stage.

Hardware component: The materials used at this stage include the following; PVC pipe $\varnothing 2 \mathrm{~mm}$, Servo motor with servo arm, $2 \mathrm{~mm}$ thick engineered wood, A thick layer of hard structured foam, An LCD Screen, A thin long sensor rod, A programmed circuit board. The engineered wood was cut to a size of $15 \mathrm{~cm} \times 10 \mathrm{~cm}$. A hole of a $\varnothing 2 \mathrm{~mm}$ was bored through at $5 \mathrm{~cm}$ from one of the breadth edges. The PVC pipes were constructed to form a $90^{\circ}$ angle. This was used to house the wire connectors from the circuit board to the servo motor. It had adjustable fixtures for increasing and decreasing the height of the millage gauge. The engineered wood serves as a base, while the thick 
layered foam serves as a housing for the circuit board and the LCD screen. The servo motor is hinged and attached to the other end of the PVC pipe and the sensor rod is hooked to the servo arm as shown in Plate 5. The servo arm moves in a clockwise direction (figure.1) and the calculations are shown below.

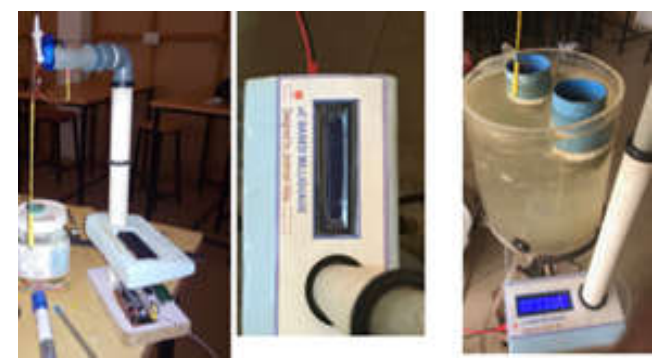

Plate 5: Electromechanical measuring device

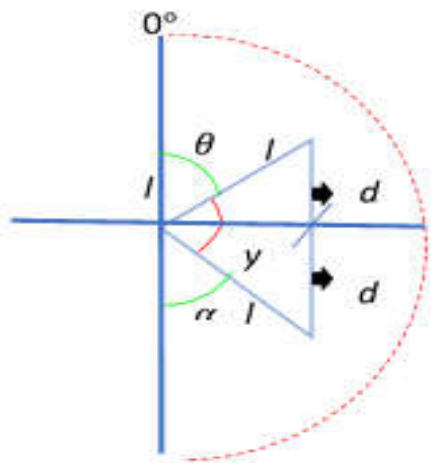

Fig 1: Servo movement

Mathematical considerations and calculations:

For angle between $0^{\circ}$ to $90^{\circ}$

Servo Arm Angle $=\theta^{\circ}$

Length of Servo Arm $=l$

$\alpha=90^{\circ}-\theta$

$d_{1}=l \sin \alpha$

Therefore; $\quad$ displacement $=l-d_{1}$

For angle above $90^{\circ}$

$y^{0}=\theta-90^{0}$

$d=l \sin y^{0}$

Therefore; $\quad$ displacement $=l+d_{1}$

Software component:_The software component was designed to drive the servo motor and recognise the remote control used to operate the servo motor. The line of codes for the whole program can be seen in the appendix section. A summary of the software programme is explained below;

Main program

Set up the $\mathrm{I} / \mathrm{O}$ pins

Set up the serial port

Print ("Press A to take $1^{\text {st }}$ measurement")

Main Loop

Check the status of $\mathrm{R}_{\mathrm{A}}-$ Test the Remote Button A pin
If $\mathrm{R}_{\mathrm{A}}$ Status $==$ Low

*do nothing*

Else

val = "ReadValue" - Execute sub-program

"ReadValue"

Print the value of "val" to the LCD

Print ("Press B to take $2^{\text {nd }}$ measurement")

Wait until $R_{B}$ goes high - $R_{B}$ (Remote Button $B$ pressed)

$\mathrm{Val}_{2}=$ "Read Value" - Execute sub-program "ReadValue"

Print the value of $\mathrm{Val}_{2}$ to the LCD.

ReadValue () - SUB PROGRAM

Displacement $=0$

Angle $=0$

Soil Sampling Procedure: Borings come in two main varieties, large-diameter and small-diameter. Largediameter borings are rarely used due to safety concerns and expense but are sometimes used to allow a geologist or engineer to visually and manually examine the soil and rock stratigraphy in-situ. Smalldiameter borings are frequently used to allow a geologist or engineer to examine soil or rock cuttings or to retrieve samples at depth using soil samplers, and to perform in-place soil tests.

\begin{tabular}{|c|c|c|c|}
\hline Site Name & $\begin{array}{l}\text { Sample } \\
\text { Notation }\end{array}$ & Coordinate & $\begin{array}{l}\mathrm{ELV} \\
(\mathrm{m})\end{array}$ \\
\hline A.B.U Dam & $\mathrm{A}$ & $11^{\circ} 826^{\prime \prime N} 7^{\circ} 39^{\prime 2} \mathrm{E}$ & 650 \\
\hline $\begin{array}{l}\text { Alex Ribadu } \\
\text { Hostel }\end{array}$ & B & $11^{\prime \prime} 9^{\prime} 15^{\prime \prime} \mathrm{N} 739^{\prime} \mathrm{E}$ & 660 \\
\hline $\begin{array}{l}\text { Basawa } \\
\text { Bridge }\end{array}$ & $\mathrm{C}$ & $11^{\circ} 9^{\prime} 46^{\prime \prime} \mathrm{N} 70^{\circ} 50^{\prime \prime} \mathrm{E}$ & 620 \\
\hline Hanwa & $\mathrm{D}$ & $11^{\circ} 722^{\prime \prime} 7^{\circ} 4228^{\circ} \mathrm{E}$ & 660 \\
\hline $\begin{array}{l}\text { UBEB } \\
\text { Secrétariat } \\
\text { Kongo }\end{array}$ & E & $11^{\circ} 48^{\prime \prime} 7^{\circ} 43^{\prime} 15^{\prime \prime} \mathrm{E}$ & 620 \\
\hline $\begin{array}{l}\text { A.B.U Area } \\
\text { 'F' Block of } \\
\text { flats }\end{array}$ & $\mathrm{F}$ & $11^{\circ} 5^{\prime} 48^{\prime \prime} 7^{\circ} 43^{\prime} 15^{\circ} \mathrm{E}$ & 620 \\
\hline Shika Bridge & G & $\begin{array}{l}11^{\circ} 11^{\prime} 46^{\prime \prime} \mathrm{N} 7^{\circ} 34^{\prime} 28^{\prime \prime} \\
\mathrm{E}\end{array}$ & 660 \\
\hline River Kubani & $\mathrm{H}$ & $11^{\circ} 9^{\prime} 34^{\prime \prime} \mathrm{N} 7037^{\prime} 55^{\circ} \mathrm{E}$ & 660 \\
\hline
\end{tabular}

Soil samples are often categorized as being either "disturbed" or "undisturbed;" however, "undisturbed" samples are not truly undisturbed Investigation (2017). Hence in this study, a pitch barrel sampler otherwise called a ring sampler was used to collect undisturbed soil samples at a depth of $10 \mathrm{~cm}$ from the surface. Three undisturbed samples each were taken from eight different locations around Zaria for testing and evaluating the performance of the improvised permeameter. Table 2 shows the locations and coordinates where the soil samples were taken. 
Study area: The research was conducted within Ahmadu Bello University Zaria at different locations - Department of Civil Engineering workshop, Department of Water Resources and Environmental Engineering Hydraulics Laboratory, Department of Soil Physics Laboratory.

Testing of improvised permeameter: The undisturbed samples obtained in the core samples from the ten locations at a shallow depth and in three replications each were taken to the laboratory and each was covered with a piece of muslin cloth held in place with a rubber band. The samples were placed with the covered end down in a shallow bowl filled with water to a depth just below the top of the samples and allowed to saturate for twenty-four hours.

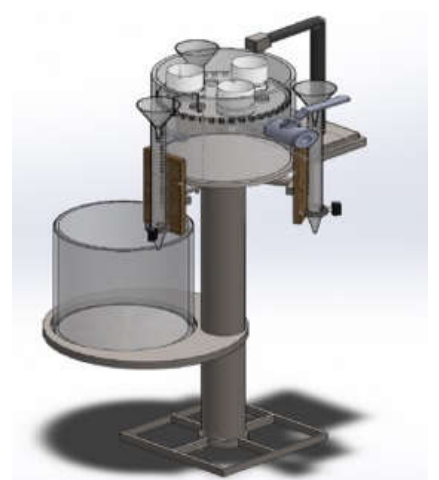

Fig 2: Assembled view of the Improvised Soil Permeameter

The completely saturated soil samples were afterwards removed from the water and affixed to cylindrical core sample holders, held in place by the gasket to ensure a tight-fitting and to prevent water from passing through the sides of the cylindrical core sampler holder. The water supply to the transparent cylindrical permeameter box was turned on and the samples placed inside the permeameter. A U-tube siphon which is used to connect the water above the soil sample in the sampler holder and the calibrated burette was filled with water and placed inside the permeameter. As the water rose inside the sampler holder, it was transmitted through the U-tube to a measuring burette where the volume ' $\mathrm{V}$ ' is measured in a given time ' $\mathrm{t}$ ' which is the duration it takes to reach that volume pending on the rate of flow. For accuracy, a large volume is used for high flow and small volume for low flow.

After the volume has been measured, the siphon is removed and the head of water in the sampler holder and the permeameter are measured (head in and head out) respectively. The hydraulic conductivity was calculated using the formula;
$\mathrm{K}=\left(\frac{\mathrm{V}}{\mathrm{At}}\right)\left(\frac{\mathrm{L}}{\mathrm{H}^{+}-\mathrm{H}^{-}}\right)$

where; $\mathrm{A}$ is the cross-sectional area in the sample $\left(\mathrm{cm}^{2}\right), \mathrm{L}$ is the length of the sample $(\mathrm{cm}), \mathrm{V}$ is the volume of water $\left(\mathrm{cm}^{3}\right)$ or $(\mathrm{ml}), \mathrm{t}$ is the time it takes to obtain the volume of water (secs), $\Delta \mathrm{H}$ or $\left(\mathrm{H}^{+}-\mathrm{H}^{-}\right)$is the difference in the head $(\mathrm{cm})$

Particle size analysis: The particle size analysis was carried out following the procedure as described by (Materials 2008). This method quantitatively determines the physical proportions of three sizes of primary soil particles as determined by their settling rates in an aqueous solution using a hydrometer. Proportions are represented by stated class sizes: sand ranging from $2000-50 \mu \mathrm{m}$; silt ranging from $50-2.0$ $\mu \mathrm{m}$ and clay $<2.0 \mu \mathrm{m}$ and those stated by the USDA Soil Survey and Canadian Soil Survey Committee. Settling rates of primary particles are based on the principle of sedimentation as described by Stokes' Law and measured using a hydrometer.

Calculations

Results are reported to the nearest $0.1 \%$ content:

$\% S=\frac{\text { (oven dry soil mass })-\left(\mathrm{R}_{\text {sand }}-\mathrm{RC} 1\right)}{(\text { oven dry soil mass })} \times 100$

(8)

$\% C=\frac{\left(\mathrm{R}_{\text {clay }}-\mathrm{RC} 2\right)}{\text { (oven dry soil mass })} \times 100$

(9)

$\% S L=100-($ Sand $\%+$ Clay $\%)$

(10)

Where $\mathrm{S}=$ sand; $\mathrm{C}=$ clay and $\mathrm{SL}=$ silt

Calibration: For the Improvised Permeameter to be standardized, a calibration process was carried by statistically comparing the Ksat values obtained from the Improvised Permeameter with the Ksat values from the Foreign Permeameter. The statistical tool used for this comparison was the Regression analysis.

\section{RESULTS AND DISCUSSION}

SolidWorks (CAD) Modelled Soil Permeameter: Figure 2 shows the isometric view and finished assembled view of the Improvised Soil Permeameter. This consists of different parts that were designed based on standard dimensions. Each part was designed independently. Figure 3 shows the exploded view of the Improvised Soil Permeameter. Here, the detailed individual parts that compose the assembly in Figure 2 is clearly illustrated. Figure 4 simply depicts the identification of the different parts of the Improvised 
Soil Permeameter. Figure 5 clearly shows the projection (Engineering) drawing of the Improvised Soil Permeameter which includes the top view, side view and the isometric view of the Improvised Soil Permeameter. Also, the detailed dimensions and units are clearly shown. Figure 6 shows the strength analysis of the frame support for the Improvised Soil Permeameter.

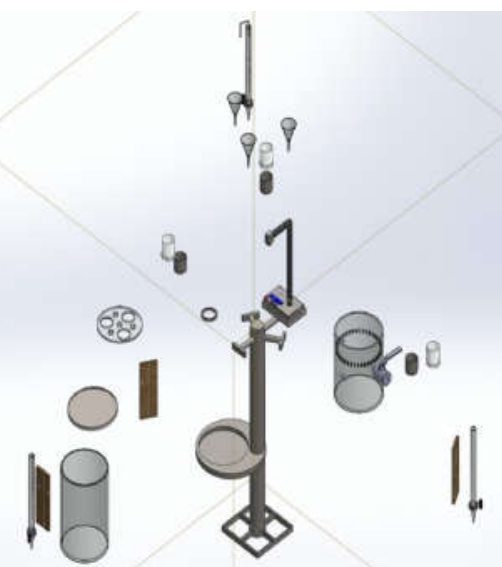

Fig 3: Exploded view of the Improvised Soil Permeameter

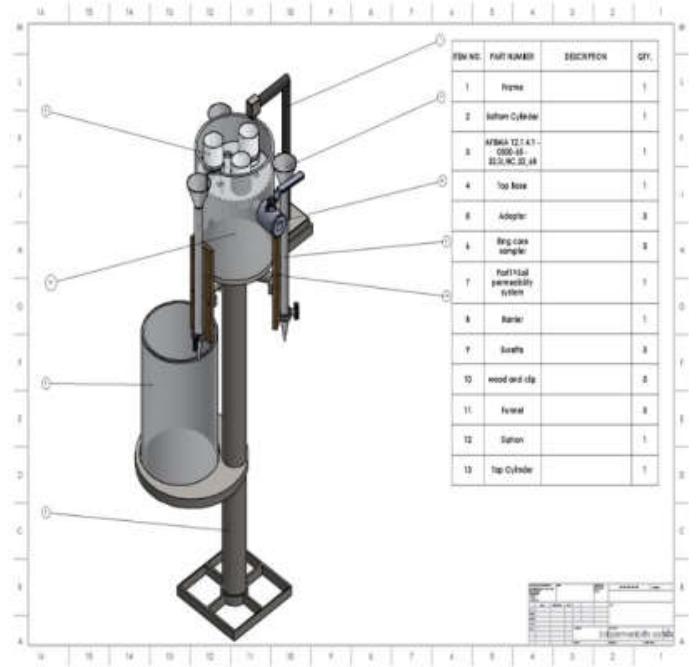

Fig 4: Parts Identification of the Improvised Soil Permeameter

The maximum permissible stress was calculated by determining the total load that will be imposed on the frame support as reflected from a total volume in Table 1. Also, it shows a deformation scale (Von Mises) and the location where this deformation $(2.31339 \mathrm{e}-008$ $\mathrm{N} / \mathrm{mm}$ ) is likely to occur. It can be seen from the figure that the deformation is likely to occur at the rotating body where the ball bearing is attached.

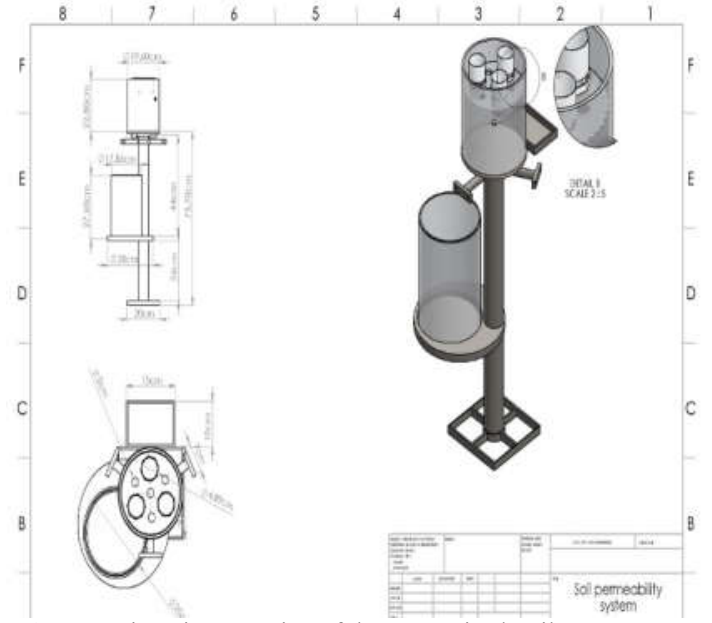

Fig 5: Engineering Drawing of the Improvised Soil Permeameter

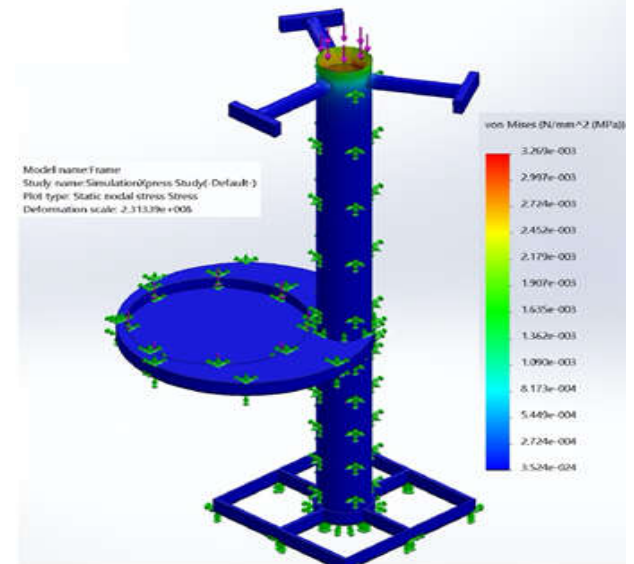

Fig 6: Strength Analysis of the Improvised Soil Permeameter

Particle size analysis of soil samples: Each sampled soil as shown in Table 2 was categorised based on their textural class as described by the particle size analysis. The result of the analysis is shown in Table 3.

\begin{tabular}{ccccl}
\multicolumn{5}{c}{ Table 3: Particle size analysis corrected to $20^{\circ} \mathrm{C}$} \\
\hline Sample & $\begin{array}{l}\text { Clay } \\
\mathbf{\%}\end{array}$ & $\begin{array}{l}\text { Silt } \\
\mathbf{\%}\end{array}$ & $\begin{array}{l}\text { Sand } \\
\mathbf{\%}\end{array}$ & $\begin{array}{l}\text { Textural } \\
\text { class USDA }\end{array}$ \\
\hline $\mathrm{A}$ & 32 & 42 & 26 & C.L \\
$\mathrm{B}$ & 30 & 30 & 40 & C.L \\
$\mathrm{C}$ & 20 & 46 & 34 & $\mathrm{~L}$ \\
$\mathrm{D}$ & 10 & 16 & 74 & S.L \\
$\mathrm{E}$ & 30 & 54 & 16 & S.C.L \\
$\mathrm{F}$ & 12 & 22 & 66 & S.L \\
Where; L $=$ loam, C.L = clay loam, S.L = sandy loam, S.C.L $=$ \\
silty clay loam
\end{tabular}

From table 3 above, it can be observed that two of the sampled soils fell within the sandy loam (SL) textural class. The soil sample ' $E$ ' and "C" fell in the silty clay loam (SCL) and loam (L) textural class respectively. Finally, two of the sampled soils were found to be within the clay loam(CL) textural class. 
Saturated hydraulic conductivity: The undisturbed sampled soils were tested for their hydraulic conductivities on both improvised and foreign permeameters as described in chapter 2.7. The mean hydraulic conductivity of the replicated soil samples with the same soil texture is shown in Table 4.

Table 4: Hydraulic conductivity data from improvised soil permeameter and Eijkelkamp permeameter

\begin{tabular}{|c|c|c|c|}
\hline \multirow{2}{*}{ Sample } & \multirow{2}{*}{$\begin{array}{l}\text { Soil } \\
\text { texture }\end{array}$} & \multicolumn{2}{|l|}{$K_{\text {sat }}(\mathrm{cm} / \mathrm{sec})$} \\
\hline & & Improvised & Eijkelkamp \\
\hline A & C.L & 0.004 & 4.547 \\
\hline B & C.L & 0.002 & 1.137 \\
\hline $\mathrm{C}$ & $\mathrm{L}$ & 0.004 & 4.547 \\
\hline $\mathrm{D}$ & S.L & 0.004 & 4.774 \\
\hline $\mathrm{E}$ & S.C.L & 0.001 & 2.076 \\
\hline \multirow[t]{3}{*}{$\mathrm{F}$} & S.L & 0.005 & 1.990 \\
\hline & Mean & 0.003 & 3.178 \\
\hline & $\mathrm{SD}$ & 0.002 & 1.618 \\
\hline
\end{tabular}

Table 4 shows a summary of the Ksat values obtained from the improvised soil permeameter and Eijkelkamp Equipment (foreign permeameter).

Comparison of saturated hydraulic conductivity: Results of the $\mathrm{K}_{\text {sat }}$ values from the improvised and foreign permeameters were compared against each other to check the measure of variation between them.

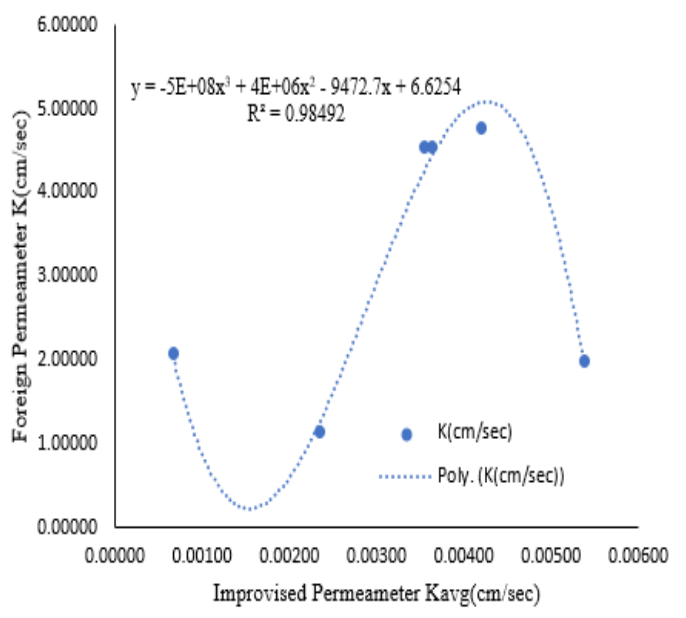

Fig 7: Comparison between Improvised Permeameter and Foreign Permeameter Ksat values

Figure 6 shows the relationship between the Improvised permeameter $(N=6)$, associated with Ksat values $M=0.00329(S D=0.00162)$ and the Foreign Permeameter $(N=6)$, associated with a numerically larger Ksat value $M=3.178(S D=1.618)$. The graph above was achieved by subjecting both sets of Ksat values to the third-order polynomial regression analysis. From the $R^{2}=0.98492$, it depicts that there is a very strong relationship between the Ksat values obtained from both Permeameters. The result of the regression analysis was obtained as;

$$
Y=-5 E+08 x^{3}+4 E+06 x^{2}-9472.7 x+6.6254
$$

Where; $X=$ Ksat values from the improvised soil permeameter; $\mathrm{Y}=$ Ksat values from Foreign Permeameter

In other words, the Ksat value obtained from the improvised soil permeameter should be inserted into the equation (11) as " $\mathrm{X}$ ", to obtain the actual value "Y" that would have been gotten from Foreign Permeameter.

Conclusion: This study has produced an automated Digital Milligauge (Electromechanical Measuring Device) which can measure water head difference and a soil permeameter which can be used for both illustrations to students and for carrying out research studies that involve hydraulic conductivity is now possible. This soil permeameter could serve as a prototype for the manufacturing sector.

\section{REFERENCES}

Carvalho, MC (2016). Practical Laboratory Automation: Made Easy with AutoIt. Hoboken, NJ: John Wiley \& Sons.

Fabian, J; Young, T; Peyton, JC; Clayton, GM (2014). Integrating the Microsoft Kinect with Simulink: Real-time object tracking example. IEEE/ASME Trans. Mechatron. 2014, 19, 249257.

Gupta, P; Alam, J; Muzzammil, M (2016). Influence of thickness and position of the individual layer on the permeability of the stratified soil. Perspect. Sci. 8. 757-759

Robotic Laboratory Automation. (2002, January 18). Retrieved

https://science. Sciencemag.org/content $\quad$ /295/5554/517. abstract

Shaun Bebbington (2014). "What is coding". Retrieved from http://yearofcodes.tumblr.com/what-iscoding2014-03-03 